\title{
Sauerkraut and sour turnip consumption habits in Slovenia
}

\author{
Martina Nagode, Katja Bezek \\ University of Primorska, Faculty of Health Sciences, Polje 42, 6310 Isola, Slovenia \\ martina.nagode@hotmail.com; katja.bezek@fvz.upr.si
}

\begin{abstract}
Introduction: Fermentation is one of the earliest methods of food preservation. Along with the extended shelf life of foods, the fermentation process provides also higher safety and better organoleptic properties of the products. The fermentation can be carried out by the naturally occurring microbial community or by the addition of the so-called starter cultures. The metabolic activity of microorganisms significantly affects the bioavailability and concentration of bioactive compounds in the product. However, the viability and number of beneficial living microorganisms depend on many factors, such as storage and processing conditions of the foods. Methods: In order to obtain the data on the knowledge and eating habits of sauerkraut and sour turnip among Slovene people, an online questionnaire was prepared. The obtained data were analysed using IBM SPSS Statistics 26 and Microsoft Excel. Results: In the present questionnaire-based survey 175 individuals were included $(24 \mathrm{M} ; 151 \mathrm{~W})$. The majority of the participants showed great knowledge about fermented foods and their health benefits. Moreover, half of participants prepare fermented foods at home. In the last month the vast majority consumed cooked ( $\mathrm{n}=$ 152) or raw $(\mathrm{n}=121)$ sauerkraut, while the lower proportions consumed cooked $(n=54)$ or raw turnip $(n=95)$. Only a few $(n=14)$ did not consume any. Among consumers on average $204 \mathrm{~g}$ of cooked and $179 \mathrm{~g}$ of raw sauerkraut and $188 \mathrm{~g}$ of cooked and $136 \mathrm{~g}$ of raw sour turnip was consumed in the last month. Discussion and conclusion: By regular and adequate consumption of sauerkraut and sour turnip, both raw and heat-treated, a beneficial effect on the immune and digestive system and the general health of the working-age population could be achieved. However, live probiotic microorganisms can positively affect human health only when consumed in sufficient concentration, which is at least $10^{8}$ to $10^{10} \mathrm{CFU}$ per day. The last could be achieved by a daily intake of
\end{abstract}


$100 \mathrm{~g}$ of product with at least $10^{6} \mathrm{CFU} \mathrm{ml^{-1 }}$ live microorganisms.

Considering this study results, the intake of live microorganisms only

by raw sauerkraut or turnip consumption among Slovene people is not

sufficient to achieve a probiotic effect.

Keywords: sauerkraut, sour turnip, fermentation, microorganisms

\section{Introduction}

Fermentation is a traditional food preservation method used to extend shelflife, safety, and impart desirable organoleptic properties of the foods (Shiferaw Terefe, 2016). This food processing technology utilizes the growth and metabolic activity of microorganisms for the stabilization and transformation of food raw materials (Di Cagno, Coda, De Angelis and Gobbeti, 2013). Fermentation of vegetables, fruits, and grains most often includes lactic acid fermentation involving different species of lactic acid bacteria (LAB) (Steinkraus, 1992). In addition to spontaneous fermentation, the controlled fermentation can be carried out by the addition of starter culture, a standardized community of microorganisms. However, the diversity of the microbiota markedly depends on the intrinsic and extrinsic parameters of the plant matrix (Di Cagno et al., 2013). Furthermore, the growth of spoilage and pathogenic organisms is inhibited by high salt concentrations, LAB metabolites, and the consequent decline of $\mathrm{pH}$ value (Shiferaw Terefe, 2016).

Sauerkraut is one of the most common and oldest forms of raw vegetable preservation. It is produced by spontaneous fermentation of cabbage under anaerobic conditions, with the addition of salt. The fermentation process takes several weeks at a temperature of 15 to $20^{\circ} \mathrm{C}$ (Oregon et al., 2016). Important strains of bacteria present in sauerkraut are Leuconostoc mesenteroides, Lactobacillus plantarum, and other genera like Leuconostoc, Lactobacillus, Pediococcus and Weissella (Touret, Oliveira and Semedo - Lemsaddek, 2018). Like sauerkraut, the sour turnip was an important food in ancient times, consumed mainly in the winter months. Raw material is prepared by placing the washed turnip into a vat, in Italian culture the turnip was alternatively layered with grape skins. Before covering the vat, a mix of water and salt or water only is added and left for 30 to 40 days at 12 to $15^{\circ} \mathrm{C}$. The most commonly represented LAB are Lactobacillus hilgardii and Pedicoccus parvulus (Maifreni, Marino and Conte, 2004). Nevertheless, due to the presence of live microorganisms that possess probiotics properties, antimicrobial, antioxidant and peptide production, fermented foods are known for its beneficial nutritional and functional properties for consumer's health (Septembre-Malaterre, Remize and Poucheret, 2018; Şanlier, Gökcen and Sezgin, 2017).

\section{Methods}

In the first part of the study literature review on the fermentation process with the focus on vegetables was made including the scientific articles not older than 
10 years. To obtain the data on the knowledge and eating habits of sauerkraut and sour turnip among Slovene people, an online questionnaire was prepared. The obtained data were processed using Microsoft Excel and SPSS Statistics 26.o (IBM, Armonk, NY, USA).

\section{Results}

The health benefits of fermented vegetables can be associated with their prebiotic and/or probiotic potential, due to the presence of live microorganisms and their metabolites, such as bioactive peptides, short-chain fatty acids or polysaccharides (Septembre-Malaterre, et al., 2018; Şanlier et al., 2017). Probiotics are live microorganisms that, when consumed in sufficient amounts, may confer a health benefit for the host (FAO/WHO, 2002). They help maintain good balance and composition of the intestinal flora, preventing the invasion of pathogenic microorganisms (Tripathi and Giri, 2014), improve immunity and calcium absorption, reduce the risk of intestinal diseases (Homayouni, Pavahoo and Azizi, 2012), lower serum cholesterol and blood pressure (Rašić, 2003). Most of the commercially used probiotics belong to LAB group, including Lactobacillus, Leuconostoc, Streptococcus, and Enterococcus genera (Yadav, 2017). To achieve positive effects, foods should contain the required minimum number of live microorganisms with a probiotic effect at the time of ingestion. The recommended standard for probiotics live cell counts is at least $10^{6} \mathrm{CFU} \mathrm{mL}^{-1}$ of the product (Neffe-Skocińska, Rzepkowska, Szydłowska and Kołożyn-Krajewska, 2018). Furthermore, many LAB species have antimicrobial activity due to the production of antimicrobial active metabolites, such as organic acids, hydrogen peroxide and other compounds, such as bacteriocins and antifungal peptides (Reis, Paula, Casarotti and Penna, 2012). Moreover, produced bioactive peptides are known for the functional properties, such as immunomodulatory, antithrombic and antihypertensive effect (Tamang et. al., 2016).

In the present study, we focused mainly on sauerkraut and sour turnip, both a result of $\mathrm{LAB}$ fermentation. In data analysis of a questionnaire-based survey 175 individuals were included (24 M; $151 \mathrm{~W}$ ). Based on the study results, the majority of the participants showed excessive knowledge about fermented foods and their health benefits (Table 1). To begin with, half of the participants prepare fermented foods at home. The majority ( $>60 \%)$ of them agreed with statements as follows: (i) salt addition inhibits the action of unwanted microorganisms and allows the reproduction of the desired ones; (ii) temperature is an important factor in the fermentation process; (iii) an anaerobic environment must be established for fermentation; (iv) sugars are converted to acids during fermentation and (v) that the $\mathrm{pH}$ of the food before and after fermentation varies. Although, the majority of them knew that fermented foods have an extended shelf life ( $81 \%)$, only half of them agreed that fermented foods are more microbiologically safe. 


\begin{tabular}{llll}
\multicolumn{1}{c}{ Statement } & I do not agree & $\begin{array}{c}\text { I neither agree } \\
\text { not disagree }\end{array}$ & I agree \\
$\begin{array}{l}\text { We need to add salt, which inhibits the action of } \\
\text { unwanted microorganisms and allows the repro- } \\
\text { duction of the desired ones. }\end{array}$ & $14(8 \%)$ & $34(19 \%)$ & $127(73 \%)$ \\
\hline $\begin{array}{l}\text { Temperature is an important factor in the fermen- } \\
\text { tation process. }\end{array}$ & $6(3 \%)$ & $18(10 \%)$ & $151(86 \%)$ \\
\hline $\begin{array}{l}\text { We need to provide anaerobic conditions. } \\
\text { In the fermentation process, sugars are converted }\end{array}$ & $13(7 \%)$ & $50(23 \%)$ & $112(64 \%)$ \\
\hline $\begin{array}{l}\text { to acids. } \\
\text { The pH value of a food changes (pH value allows us }\end{array}$ & $2(1 \%)$ & $24(14 \%)$ & $112(64 \%)$ \\
\hline $\begin{array}{l}\text { Fe define a substance as acidic, neutral or basic). } \\
\text { Fermented foods have an extended shelf life. }\end{array}$ & $7(4 \%)$ & $27(15 \%)$ & $141(81 \%)$ \\
\hline $\begin{array}{l}\text { Fermented foods are more microbiologically safe. } \\
\text { Fermented foods are richer in vitamins. }\end{array}$ & $14(8 \%)$ & $67(38 \%)$ & $94(54 \%)$ \\
\hline
\end{tabular}

Regarding the consumption in the last month, the vast majority consumed cooked $(n=152)$ or raw $(n=121)$ sauerkraut, while the lower proportions consumed cooked $(n=54)$ or raw turnip $(n=95)$. Only a few $(n=14)$ did not consumed any. On average $204 \pm 176 \mathrm{~g}$ of cooked and $179 \pm 150 \mathrm{~g}$ of raw sauerkraut and $188 \pm 172 \mathrm{~g}$ of cooked and $136 \pm 136 \mathrm{~g}$ of raw sour turnip was consumed in the last month.

\section{Discussion}

During food fermentation, functional microorganisms transform raw material constituents, thereby enhancing the nutrition value, sensory properties and safety, degrading toxic substances, producing antioxidant and antimicrobial substances (Tamang Shin et al., 2016). Sauerkraut and sour turnip are locally produced processed vegetables and are also used as major components of traditional Slovenian foods (Korošec, Golob, Bertoncelj, Stibil and Koroušić Seljak, 2013). As expected, this study participants showed good knowledge about the fermentation process. Surprisingly, the lowest level of agreement was for a statement about the fermented foods being a better source of vitamins than raw material. However, as reviewed before, the probiotic, antimicrobial and antioxidant effects of fermented vegetables have a beneficial potential for human health (Tamang Shin et al., 2016). We focused mainly on the probiotic effects of sauerkraut and sour turnip. Live microorganisms with a probiotic potential can have a positive effect on our health only if consumed in sufficient amount, which means at least $10^{8}$ to $10^{10} \mathrm{CFU}$ per day (FAO/WHO, 2002). This

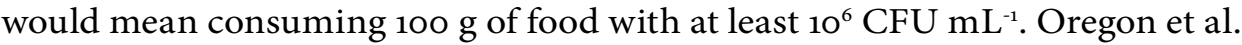
(2016) found that $100 \mathrm{~g}$ of sauerkraut contains $5 \times 10^{6} \mathrm{CFU}$. Considering present study results, the intake of live microorganisms e.g. by $179 \mathrm{~g}$ of raw sauerkraut per month, meaning $3 \times 10^{5} \mathrm{CFU}$ per day is not in accordance with recommendations. Furthermore, the microorganisms found in sauerkraut and sour turnip are diverse and not all have probiotic effects (Zabat, Sano, Wurster, Cabral 
and Belenky, 2018). It should also be noticed that many fermented foods are heat-treated after fermentation to enhance food safety, which can significantly influence the number of microorganisms (Rezac, Kok, Heermann and Hutkins, 2018).

\section{Conclusions}

The live microorganisms with probiotic properties present in fermented foods have a beneficial effect on intestines, prevent the action of pathogenic microorganisms, improve the immune system, and general health. Considering this study results, the intake of live microorganisms only by raw sauerkraut or sour turnip consumption among Slovene people is not sufficient to achieve a probiotic effect. Therefore, the intake of probiotic microorganisms with other foods or dietary supplements is recommended. With regard of the questionnaire results, the benefits of Slovene traditional food should be more promoted.

\section{References}

Di Cagno, R., Coda, R., De Angelis, M. and Gobbeti, M., 2013. Exploitation of vegetables and fruits through lactic acid fermentation. Food Microbiology, vol. 33, no. 1, pp. 1-10. [viewed 28 June 2020]. Available from: https:// www.sciencedirect.com/science/article/abs/pii/So740002012001943?via\%3 Dihub

Food and agriculture organization (FAO) and World health organization (WHO), 2002. Report of a joint FAO/WHO working group report on drafting guidelines for the evaluation of probiotics in food [online]. [viewed 30 June 2020]. Available from: http://www.who.int/foodsafety/ fs_management/en/probiotic_guidelines.pdf

Homayouni, A., Payahoo, L. and Azizi, A., 2012. Effects of Probiotics on Lipid Profile: A Review. Effects of Probiotics on Lipid Profile: A Review, vol. 7, no. 5, pp. 251-265. [viewed 26 June 2020]. Available from: https://dx.doi. org/10.3923/ajft.2012.251.265

Korošec, M., Golob, T., Bertoncelj, J., Stibilj, V. and Koroušić Seljak, B., 2013. The Slovenian food composition database. Food Chemistry, vol. 130, no. 3, pp. 495-499. [viewed 30 June 2020]. Available from: https://www.sciencedirect. com/science/article/abs/pii/So308814613000071?casa_token=TAoZIxNbHyIAAAAA:ZzCXT86IHTC733Is4b7wfJd1NgO9P8QE04qDZrNo5zmjoqg2FinKST63G336ahYKgo493yJkoR8

Maifreni, M., Marino, M. and Conte, L., 2004. Lactic acid fermentation of Brassica rapa: Chemical and microbial evaluation of a typical Italian product (Brovada). European Food Research and Technology, vol. 218, no. 5, pp. 469-473. [viewed 26 June 2020]. Available from: https://doi.org/10.1007/ s00217-004-0877-6 
Neffe-Skocińska K., Rzepkowska A., Szydłowska A. and Kołożyn-Krajewska D., 2018. Alternative and Replacement Foods. Academic Press; Cambridge, MA, USA: 2018. In: Trends and Possibilities of the Use of Probiotics in Food Production, pp. 65-94. [viewed 26 June 2020]. Available from: https://scholar.google.com/scholar_lookup?title=Alternative+and+Replac ement+Foods\&author $=$ K.+Neffe-Skoci\%C5\%84ska\&author=A.+Rzepkows ka\&author $=$ A.+Szyd\%C5\%820wska\&author=D.+Ko\%C5\%820\%C5\%BCynKrajewska\&publication_year $=2018 \&$

Oregon, R. P., Corbin, A. and Scott, B., 2016. Sauerkraut: A Probiotic Superfood. Functional Foods in Health and Disease 2016, vol. 6, no. 8, pp. 536543. [viewed 26 June 2020]. Available from: https://www.ffhdj.com/index. $\mathrm{php} / \mathrm{ffhd} / \mathrm{article} / \mathrm{view} / 262 / 519$

Rašić, J. L., 2003. MICROFLORA OF THE INTESTINE - Probiotics. Encyclopedia of Food Sciences and Nutrition (Second Edition), pp. 3911-3916. [viewed 26 June 2020]. Available from: https://doi.org/10.1016/Bo-12227055-X/00776-8

Reis, J. A., Paula, A. T., Casarotti, S. N. and Penna, A. L. B., 2012. Lactic Acid Bacteria Antimicrobial Compounds: Characteristics and Applications. Food Engineering Reviews, vol. 4, pp. 124-140. [viewed 30 June 2020]. Available from: https://link.springer.com/article/10.1007/s12393-012-9051-2

Rezac, S., Kok, C. R., Heermann, M. and Hutkins, R., 2018. Fermented Foods as a Dietary Source of Live Organisms. Frontiers in Microbiology. [viewed 30 June 2020]. Available from: https://www.frontiersin.org/articles/10.3389/ fmicb.2018.01785/full

Şanlier, N. Gökcen, B. B. and Sezgin, A. C., 2017. Health benefits of fermented foods. Critical Reviews in Food Science and Nutrition, vol. 59, no. 3, pp. 506-527. [viewed 30 June 2020]. Available from: https://www.tandfonline. com/doi/abs/10.1080/10408398.2017.1383355?journalCode=bfsn2o

Septembre-Malaterre, A., Remize, F. and Poucheret, P., 2018. Fruits and vegetables, as a source of nutritional compounds and phytochemicals: Changes in bioactive compounds during lactic fermentation. Food Research International, vol. 104, pp. 86-99. [viewed 30 June 2020]. Available from: https:/www.sciencedirect.com/science/article/abs/pii/ So963996917305987?via\%3Dihub

Shiferaw Terefe N., 2016. Food Fermentation. CSIRO Food and Nutrition. [viewed 28 June 2020]. Available from: https://www.sciencedirect.com/science/article/pii/B978008100596503420X?via\%3Dihub

Steinkraus, K. H., 1992. Applications of Biotechnology to Fermented Foods [online]. Washington: National Academies Press. [viewed 28 June 2020]. Available from: https://www.ncbi.nlm.nih.gov/books/NBK234703/

Tamang, J. P., Shin, D. H., Jung, S. J. and Chae, S. W., 2016. Functional Properties of Microorganisms in Fermented Foods. Frontiers in Microbiolo- 
gy, vol. 7, no. 578. [viewed 27 June 2020]. Available from: https://www.ncbi. nlm.nih.gov/pmc/articles/PMC4844621/pdf/fmicb-07-00578.pdf

Touret, T., Oliveira, M. and Semedo-Lemsaddek, T., 2018. Putative probiotic lactic acid bacteria isolated from sauerkraut fermentations. PloS one, vol. 13, no. 9. [viewed 26 June 2020]. Available from: https://doi.org/10.1371/ journal.pone.0203501

Tripathi, M. K. and Giri, S. K., 2014. Probiotic functional foods: Survival of probiotics during processing and storage. Journal of Functional Foods, vol. 9, pp. 225-241. [viewed 26 June 2020]. Available from: https:/doi. org/10.1016/j.jff.2014.04.030

Yadav R., 2017. Probiotics for Human Health: Current Progress and Applications In: Shukla P., ed. Recent advances in Applied Microbiology [online]. Springer. [viewed 30 June 2020]. Available from: https://link.springer.com/ book/10.1007\%2F978-981-10-5275-0

Zabat, M. A., Sano, W. H., Wurster, J. I., Cabral, D. J. and Belenky, P., 2018. Microbial Community Analysis of Sauerkraut Fermentation Reveals a Stable and Rapidly Established Community. Foods, vol. 7, no. 5. [viewed 30 June 2020]. Available from: https:/www.ncbi.nlm.nih.gov/pmc/articles/ PMC59770971 